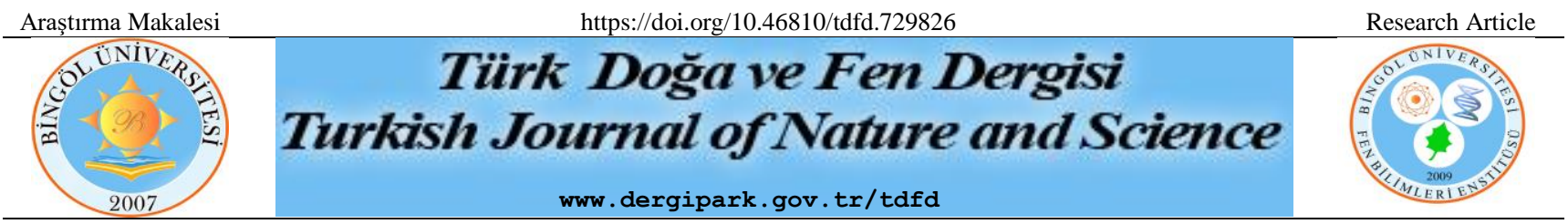

\title{
Bazı İki ve Altı Sıralı Arpa (Hordeum vulgare L.) Çeşitlerinin Isparta Koşullarında Performansları
}

\author{
Aykut ŞENER $^{1}$, Bekir ATAR ${ }^{2}$, Burhan KARA ${ }^{1}$ \\ ${ }^{1}$ Isparta Uygulamalı Bilimler Üniversitesi, Ziraat Fakültesi, Tarla Bitkileri Bölümü, Isparta, Türkiye \\ ${ }^{2}$ Isparta Uygulamalı Bilimler Üniversitesi, Atabey MYO, Bitkisel ve Hayvansal Üretim Bölümü, Isparta, Türkiye \\ Aykut ŞENER ORCID No: 0000-0003-1868-9451 \\ Bekir ATAR ORCID No: 0000-0002-1446-5699 \\ Burhan KARA ORCID No: 0000-0002-4207-0539 \\ *Sorumlu yazar: bekiratar@isparta.edu.tr
}

(Alınış: 30.04.2020, Kabul: 01.10.2020, Online Yayınlanma: 23.10.2020)

\begin{abstract}
Anahtar
Kelimeler

Arpa,

Adaptasyon,

Verim,

Verim

özellikleri

Öz: Araştırma yerli ve yabancı arpa çeşitlerinin bölgedeki verim ve verim ögelerini belirlemek amacıyla 2015-16 ve 2016-17 yıllarında yürütülmüştür. Çalışmada; üçü 2 sıralı, dördü 6 sıralı yedi arpa çeşidi tesadüf blokları deneme desenine göre 3 tekrarlamalı olarak ekilmiş ve değerlendirilmiştir. Verim ve verim özellikleri bakımından çeşitler ve yıllar arasındaki farklar istatistiksel olarak önemli olmuştur. Verim bakımından 6 sıralı Scarpia çeşidi (422 kg da-1) ile 2 sıralı Tarm-92 çeşidi (406 kg da-1) ilk iki sırada yer almıştır. Bitki boyu ve başak uzunluğu bakımından Aydanhanım, başakta tane sayısı bakımından Kıral-97, Bin tane ve hektolitre ağırlı̆̆ bakımından Tarm-92 çeşitleri öne çıkmıştır.
\end{abstract}

\section{Performances of some Two and Six Rows Barley (Hordeum vulgare L.) Cultivars in Isparta Conditions}

Keywords

Barley,

Adaptation,

Yield,

Yield

components

\begin{abstract}
The research was carried out to determine the yield and yield components of the local and foreign barley varieties in the region in the 2015-16 and 2016-17 growing seasons. In this study, seven barley varieties, three of which are in two rows, four of which are six rows, were planted at the randomized complete blocks design with four replication, and evaluated. In terms of yield and yield characteristics, the differences between varieties and years were statistically significant. In point of yield, 6-row Scarpia variety (422 $\left.\mathrm{kg} \mathrm{da}^{-1}\right)$ and 2-row Tarm-92 variety (406 $\mathrm{kg} \mathrm{da}^{-1}$ ) were in the first two places. Aydanhanim related to plant height and spike length, Kiral-97 regarding grain number in spike, Tarm-92 in terms of thousand grain and hectolitre weight came to the fore.
\end{abstract}

\section{GÍRIŞ̧}

Kültüre alınmasının üzerinden 10 bin yıldan fazla zaman geçen [1] ve tarım tarihinin en önemli ürünlerinden biri olarak yetiştirilmeye başlanan arpa (Hordeum vulgare L.) [2], son yıllarda ekim alanı ve üretim miktarı olarak gerilese de, insan ve hayvan beslenmesindeki vazgeçilmez yerini korumaktadır. Genel olarak hayvan besleme, malt yapımı ve az miktarlarda insan gidası olarak tüketilmektedir. Geniş adaptasyon yeteneği sayesinde hem Türkiye'de hem de Dünya'da geniş bir coğrafyada yetiştirilmektedir. Türkiye 7.6 milyon tonluk (2019 y1lı) üretimi ile dünya arpa üretiminin (141 milyon ton) yaklaşık \%5'ini gerçekleştirmektedir. Ancak 269 $\mathrm{kg} / \mathrm{da}$ verimi ile dünya verim ortalamasının $(265 \mathrm{~kg} / \mathrm{da})$ altındadır [3].

Genel olarak çok parçalı arazi yapısı, kültürel uygulama eksiklikleri, eksik ve yanlış gübreleme tercihleri ile yanlış çeşit seçimi gibi etkenler Türkiye'de arpa verimini düşürmektedir. Ayrıca arpa genetik özelliklerinin yanında çevre koşullarından da fazlaca etkilenen bir bitkidir $[4,5,6,7]$. Çevre koşullarından nispeten daha az etkilenen çeşitlerin geliştirilmesi 1slahçıların uğraş verdiği sorunlardandır [8]. Belirli çevre ve iklim koşullarına uygun arpa çeşitlerinin geliştirilmesi veya mevcut çeşitler içinden bölgeye uygun olanların bulunması verim ve ekonomik sürdürebilirlik açısından önem taşımaktadır. 
Son yıllarda tescil edilen çeşitlerle birlikte dünyada çok fazla çeşit bulunmaktadır. İletişimin ve nakliyenin gelişmesi ile birlikte üreticiler bu çeşitlere kolay erişim imkânı yakalamaktadır. Bölge için daha önce denenmemiş çeşit kullanımı başarısızlık ve ekonomik zarara neden olabilmektedir. Bu nedenle araştırma, yerli ve yurtdışı orjinli piyasadan temin edilebilen bazı arpa çeşitlerinin Akdeniz geçit kuşağında yer alan Isparta ekolojik koşullarında tane verimi ve bazı verim özellikleri yönünden karşılaştırılması amacıyla yürütülmüştür.

\section{MATERYAL VE METOT}

Araştırma 2015-2016 ve 2016-2017 vejetasyon döneminde Isparta Uygulamalı Bilimler Üniversitesi, Ziraat Fakültesi, Araştırma ve Deneme arazilerinde üçü Türkiye, dördü yurtdışı kökenli olmak üzere toplam yedi arpa çeşidi kullanılarak, tesadüf blokları deneme desenine göre 3 tekrarlamalı olarak yürütülmüştür. Araştırmada materyal olarak; Tarm-92 (Türkiye-2 sıralı),
Aydanhanım (Türkiye-2 siralı), Kıral-97 (Türkiye-6 siral1), Ramata (Fransa-6 siral1), Scarpia (Almanya-6 sıral1), Cervoise (Fransa-6 siralı) ve Novosadski565 (Sırbistan-2 sıralı) çeşitleri kullanılmıştır. Ekimler her bir parselde 6 sira olacak şekilde,(sıra arası $17 \mathrm{~cm}$ ve metrekareye 500 tohum hesabıyla $5 \mathrm{~m}$ uzunluğundaki parsellere yapılmıştır. Her iki deneme yılında ekimler Ekim ayınınikinci haftasında gerçekleştirilmiştir. Ekimden önce $30 \mathrm{~kg} \mathrm{da}^{-1}$ Süper Ekin ${ }^{\circledR}$ gübresi [13-25$\left.5+10\left(\mathrm{SO}_{3}\right)+\mathrm{Zn}(\% 0.5)\right]\left(3.9 \mathrm{~kg} \mathrm{~N}, 7.5 \mathrm{~kg} \mathrm{P} \mathrm{O}_{5}, 1.5 \mathrm{~kg}\right.$ $\mathrm{K}_{2} \mathrm{O}$ ve $3 \mathrm{~kg} \quad \mathrm{SO}_{3} \quad \mathrm{da}^{-1}$ ) uygulanarak toprağa karıştırılmıştır. Azotun kalan kısmı (6.1 $\left.\mathrm{kg} \mathrm{da}^{-1}\right)$ üst gübre olarak kardeşlenme döneminde amonyum sülfat $(\% 21 \mathrm{~N})$ formunda uygulanmıștır. Yağıșlar haricinde sulama yapılmamıştır. Yabancı ot mücadelesi için 2.4-D terkipli herbisit kullanılmıştır. Deneme alanı toprağı killi-tınlı bir yapıya sahip olup, hafif bazik, kireç oranı yüksek ve organik madde oranı düşük yapıdadır (Tablo 2).

Tablo 1. Deneme dönemi ve uzun y1llara ait iklim verileri*

\begin{tabular}{|c|c|c|c|c|c|c|c|c|c|c|c|c|}
\hline & Yillar & Ekim & Kasım & Aralık & Ocak & Şubat & Mart & Nisan & Mayis & Haziran & Temmuz & Ort,/Top \\
\hline Ortalama & $2015 / 16$ & 14.5 & 8.7 & 2.4 & 1.6 & 7.1 & 7.7 & 14.5 & 15.1 & 22.0 & 25.4 & 11.9 \\
\hline \multirow[t]{2}{*}{ Sicaklık $\left({ }^{\circ} \mathrm{C}\right)$} & $2016 / 17$ & 14.8 & 7.2 & 0.3 & -0.8 & 3.0 & 7.3 & 10.6 & 14.9 & 20.1 & 25.1 & 10.2 \\
\hline & Uzun yillar & 13.0 & 7.4 & 3.5 & 1.9 & 2.9 & 6.2 & 10.8 & 15.6 & 20.2 & 23.7 & 10.5 \\
\hline Toplam Yağış & $2015 / 16$ & 23.1 & 17.5 & 6.4 & 96.8 & 33.3 & 59.9 & 47.8 & 87.6 & 12.4 & 25.7 & 410.5 \\
\hline \multirow[t]{2}{*}{$(\mathrm{mm})$} & $2016 / 17$ & 1.6 & 48.8 & 33.5 & 87.8 & 3.6 & 25.6 & 149.5 & 30.9 & 13.1 & 20.4 & 414.8 \\
\hline & Uzun yillar & 37.1 & 45.9 & 82.1 & 73.6 & 64.0 & 55.3 & 55.3 & 30.6 & 14.6 & 11.7 & 470.2 \\
\hline
\end{tabular}

* Isparta Meteoroloji İstasyonu iklim verileri

Hasat her iki yılda da, tam olum döneminde, Temmuz ayının ortalarında yapılmıştır. Parsellerin yanlarından birer sıra ve uçlardan $0.5 \mathrm{~m}$ kenar etkisi atıldıktan sonra kalan kısımlar (4 sıra ve 4 metre) hasat edilmiştir. Her bir çeşitte bitki boyu, başak boyu, başaktaki tane sayısı, bin tane ağırlığı, hektolitre ağırlığı ve tane verimi ölçümleri yapılmıştır. İstatistiksel analizler TOTEMSTAT paket programı kullanılarak yapılmıştır. Ortalamalar arasındaki farklılıkların önem düzeylerini belirleyebilmek amacıyla LSD Testi kullanılmıştır.

Tablo 2. Deneme alanı toprağının bazı fiziksel analiz sonuçları*

\begin{tabular}{|c|c|c|c|c|c|c|c|c|c|}
\hline \multirow[b]{2}{*}{ Tekstür } & \multirow[b]{2}{*}{ Toplam Tuz (\%) } & \multirow[b]{2}{*}{$\mathrm{pH}$} & \multirow[b]{2}{*}{$\begin{array}{l}\text { Kireç } \\
(\%)\end{array}$} & \multirow{2}{*}{$\mathrm{CaCO}_{3}$} & \multicolumn{3}{|c|}{ Yarayışlı Besin Elementleri (kg/da) } & \multirow[b]{2}{*}{$\begin{array}{l}\text { Organik } \\
(\%)\end{array}$} & \multirow{2}{*}{ Madde } \\
\hline & & & & & $\begin{array}{l}\text { Azot }(\%) \\
\left(\mathrm{NO}_{3}\right)\end{array}$ & Fosfor $\left(\mathrm{P}_{2} \mathrm{O}_{5}\right)$ & Potasyum $\left(\mathrm{K}_{2} \mathrm{O}\right)$ & & \\
\hline Killi-tınlı & 0.019 & 7.91 & 32.44 & & 0.31 & 2.04 & 2.27 & 1.8 & \\
\hline
\end{tabular}

"ISUBÜ Ziraat Fakültesi Toprak ve Bitki Besleme Bölümü laboratuvarında yapılmıştır.

\section{BULGULAR VE TARTIŞMA}

Isparta koşullarında yetiştirilen farklı arpa çeşitlerinde incelenen özelliklerin ortalamaları ve farklılık gruplandırmaları Tablo 3'te verilmiștir. İncelenen tüm özellikler $\mathrm{P}<0.01$ düzeyinde önemli bulunmuştur. Farklı arpa çeşitlerinin bitki boyu ortalamaları incelendiğinde; 2015-16 yetiştirme sezonunda en yüksek bitki boyu Aydanhanım (78.6 cm) ve Tarm-92 $(75.9 \mathrm{~cm})$ çeşitlerinde ölçülürken, en düşük bitki boyu Kıral-97 $(53.2 \mathrm{~cm})$ ve Cervoise $(53.9 \mathrm{~cm})$ çeşitlerinde belirlenmiştir. 2016-17 üretim sezonunda bitki boyu ortalamaları $(76.5 \mathrm{~cm})$ 2015-16 sezonu ortalamalarina $(61.8 \mathrm{~cm})$ göre artış göstermiştir. 2016-17 üretim sezonunda en yüksek bitki boyu ortalamaları yine Aydanhanım $(102.5 \mathrm{~cm})$ çeşidinde ölçülmüştür. En düşük bitki boyu ortalamaları Novosadski565 $(67.0 \mathrm{~cm})$,
Cervoise $(65.1 \mathrm{~cm})$ ve Kıral-97 $(53.2 \mathrm{~cm})$ çeșitlerinde belirlenmiştir (Tablo 3).

2015-16 üretim sezonunda Aydanhanım $(8.4 \mathrm{~cm})$, Novosadski565 $(8.4 \mathrm{~cm})$ ve Tarm-92 $(8.1 \mathrm{~cm})$ çeşitlerinin başak uzunlukları en yüksek bulunmuş ve istatistiksel olarak aynı grupta yer almışlardır. 2016-17 yetiştirme sezonunda en yüksek başak uzunluğu $9.4 \mathrm{~cm}$ ile Aydanhanım çeşidinde belirlenirken, bunu sırasıyla Novosadski565 $(9.1 \mathrm{~cm})$, Scarpia $(8.7 \mathrm{~cm})$ ve Tarm-92 $(8.4 \mathrm{~cm})$ çeşitleri izlemiştir. En düşük başak uzunluğu ise Kıral-97 $(6.1 \mathrm{~cm})$ çeşidinde belirlenmiştir. Bitkide başak uzunluğu ortalamaları incelendiğinde; bitki boyunda olduğu gibi 2016-17 sezonu ortalamaları 2015-16 sezonu ortalamalarından yüksek bulunmuştur. 
Çeşitlerin başakta tane sayılarına ait ortalamalar incelendiğinde; her iki yetiştirme sezonunda da Tarm-92, Aydanhanım ve Novosadski565 çeşitlerinde en düşük değerler belirlenmiş ve aynı istatistiki grupta yer almışlardır. Bu üç çeşit 2 sıralı arpa olduğundan başakta tane sayıları 30.4 ile 22.1 başak/adet arasında değişmiştir. En yüksek başakta tane sayısı 2015-16 ve 2016-17 sezonlarında da Kıral-97 çeşidinde ölçülmüştür. Denemenin ilk yılında 2 sıralı arpa çeşitleri içinden en yüksek bin tane ağırlığı 49.6 g ile Aydanhanım çeşidinden elde edilirken, 6 sıralı arpa çeşitleri arasında en yüksek bin tane ağırlığı ortalaması 38.5 g ile Scarpia çeşidinde belirlenmiştir. Denemenin ikinci yılında en yüksek bin tane ağırlığı ortalamaları 63.3 g ile Kıral-97 çeşidinde belirlenmiştir. 6 sıralı arpa çeşitleri arasında Scarpia çeşidi $54.8 \mathrm{~g}$ ile en yüksek bin tane ağırlığına sahip çeşit olurken, Scarpia çeşidini $47.0 \mathrm{~g}$ ile Cervoise çeşidi izlemiştir. Bin tane ağırlığı, birim alan tane verime doğrudan etkisi olan önemli bir özelliktir. Scarpia çeşidi 6 sıra arpa çeşidi olmasına rağmen 2 sıralı arpa çeşitlerine yakın bin tane ağırlığı değerlerine ulaşmıştır. Bin tane ağırlığı ile birlikte başakta tane sayısının da yüksek olması birim alan tane veriminin de yüksek olması ile sonuçlanmıştır. Bin tane ağırlıkları bakımından 2015-16 sezonunda elde edilen ortalamalar 2016-17 sezonunda elde dilen ortalamalardan düşük bulunmuştur.

Hektolitre ağırlığı bakımından her iki üretim sezonunda da en yüksek değerler Tarm-92 çeşidinde belirlenirken, en düşük değerler Kıral-97 çeşidinde belirlenmiştir. Hektolitre ağırlığı ortalamaları 2015-16 sezonunda 71.2$5 ., 7 \mathrm{~kg}$ arasinda, 2016-17 sezonunda 70.2-59.8 kg arasında değişmiştir.

Tablo 3. Arpa çeşitlerinin tarımsal özelliklerine ait ortalamalar

\begin{tabular}{|c|c|c|c|c|c|c|}
\hline \multirow[t]{2}{*}{ Çeşitler } & \multicolumn{2}{|c|}{ Bitki Boyu (cm) } & \multicolumn{2}{|c|}{ Başak Uzunluğu (cm) } & \multicolumn{2}{|c|}{ Başakta Tane Sayısı (adet/başak) } \\
\hline & $2015-16$ & 2016-17 & $2015-16$ & $2016-17$ & $2015-16$ & $2016-17$ \\
\hline Ramata & $62.2^{\mathrm{b}}$ & $72.9^{\mathrm{d}}$ & $6.9^{\mathrm{b}}$ & $7.9^{\mathrm{d}}$ & $51.2^{\mathrm{c}}$ & $57.3^{\mathrm{b}}$ \\
\hline Kiral-97 & $53.2^{\mathrm{c}}$ & $61.9^{\mathrm{e}}$ & $5.8^{\mathrm{c}}$ & $6.1^{\mathrm{f}}$ & $83.0^{\mathrm{a}}$ & $66.3^{\mathrm{a}}$ \\
\hline Cervoise & $53.9^{c}$ & $65.1^{\mathrm{e}}$ & $6.8^{\mathrm{b}}$ & $7.3^{\mathrm{e}}$ & $59.9^{\mathrm{b}}$ & $55.5^{\mathrm{b}}$ \\
\hline Tarm-92 & $75.9^{\mathrm{a}}$ & $86.3^{\mathrm{b}}$ & $8.1^{\mathrm{a}}$ & $8.4^{\mathrm{c}}$ & $24.4^{\mathrm{d}}$ & $22.1^{\mathrm{c}}$ \\
\hline Aydanhanım & $78.6^{\mathrm{a}}$ & $102.5^{\mathrm{a}}$ & $8.4^{\mathrm{a}}$ & $9.4^{\mathrm{a}}$ & $30.4^{\mathrm{d}}$ & $27.2^{\mathrm{c}}$ \\
\hline Novo, 565 & $51.2^{\mathrm{c}}$ & $67.0^{\mathrm{e}}$ & $8.4^{\mathrm{a}}$ & $9.1^{\mathrm{ab}}$ & $24.9^{\mathrm{d}}$ & $24.0^{\mathrm{c}}$ \\
\hline Scarpia & $57.3^{\mathrm{bc}}$ & $79.7^{\mathrm{c}}$ & $7.1^{\mathrm{b}}$ & $8.7^{\mathrm{bc}}$ & $51.6^{\mathrm{c}}$ & $59.5^{\mathrm{b}}$ \\
\hline Yil Ort, & $61.8^{\mathrm{B}}$ & $76.5^{\mathrm{A}}$ & $7.4^{\mathrm{B}}$ & $8.1^{\mathrm{A}}$ & 46.5 & 44.6 \\
\hline Kareler Ort, & 374.03 & 615.38 & 2.85 & 3.81 & 1387.03 & 1102.72 \\
\hline F Değeri & $28.88^{* *}$ & $59.86^{* *}$ & $13.34^{* * *}$ & $51.84^{* *}$ & $68.19^{* * *}$ & $130.48^{* *}$ \\
\hline Lsd & 6.41 & 5.70 & 0.82 & 0.48 & 8.02 & 5.17 \\
\hline $\mathrm{Cv} \%$ & 5.84 & 4.19 & 6.28 & 3.34 & 9.7 & 6.52 \\
\hline \multirow[t]{2}{*}{ Çeşitler } & \multicolumn{2}{|c|}{ Bin Tane Ağırlığı (g) } & \multicolumn{2}{|c|}{ Hektolitre Ağırlığı (kg) } & \multicolumn{2}{|c|}{ Tane Verimi $\left(\mathrm{kg} \mathrm{da}^{-1}\right)$} \\
\hline & $2015-16$ & 2016-17 & $2015-16$ & 2016-17 & $2015-16$ & $2016-17$ \\
\hline Ramata & $36.5^{\mathrm{d}}$ & $49.9^{\mathrm{d}}$ & $62.6^{\mathrm{f}}$ & $68.1^{b}$ & $288^{\mathrm{b}}$ & $286^{\mathrm{c}}$ \\
\hline Kıral-97 & $29.2^{\mathrm{e}}$ & $40.3^{\mathrm{e}}$ & $57.7^{\mathrm{g}}$ & $59.8^{\mathrm{c}}$ & $278^{\mathrm{bc}}$ & $185^{\mathrm{d}}$ \\
\hline Cervoise & $38.3^{c}$ & $47.0^{\mathrm{d}}$ & $67.5^{\mathrm{c}}$ & $68.7^{\mathrm{ab}}$ & $292^{\mathrm{b}}$ & $408^{\mathrm{b}}$ \\
\hline Tarm-92 & $47.5^{\mathrm{b}}$ & $63.3^{\mathrm{a}}$ & $71.2^{\mathrm{a}}$ & $70.2^{\mathrm{a}}$ & $424^{\mathrm{a}}$ & $388^{\mathrm{b}}$ \\
\hline Aydanhanım & $49.6^{\mathrm{a}}$ & $59.0^{\mathrm{b}}$ & $70.0^{\mathrm{b}}$ & $68.0^{\mathrm{b}}$ & $321^{\mathrm{b}}$ & $389^{\mathrm{b}}$ \\
\hline Novo, 565 & $46.9^{\mathrm{b}}$ & $55.3^{\mathrm{c}}$ & $66.7^{\mathrm{d}}$ & $67.5^{\mathrm{b}}$ & $211^{\mathrm{c}}$ & $370^{\mathrm{b}}$ \\
\hline Scarpia & $38.5^{\mathrm{c}}$ & $54.8^{\mathrm{c}}$ & $63.5^{\mathrm{e}}$ & $66.8^{b}$ & $317^{\mathrm{b}}$ & $527^{\mathrm{a}}$ \\
\hline Yil Ort, & $40.9^{\mathrm{B}}$ & $52.8^{\mathrm{A}}$ & 65.6 & 68.1 & $304.4^{\mathrm{B}}$ & $364.7^{\mathrm{A}}$ \\
\hline Kareler Ort, & 161.52 & 179.43 & 65.77 & 34.13 & 12257.43 & 33894.43 \\
\hline F Değeri & $371.12^{* *}$ & $67.77^{* *}$ & $541.72^{* *}$ & $28.75^{* *}$ & $8.63^{* *}$ & $44.01^{* *}$ \\
\hline Lsd & 1.17 & 2.89 & 0.62 & 1.94 & 67.05 & 49.37 \\
\hline $\mathrm{Cv} \%$ & 1.61 & 3.08 & 0.53 & 1.63 & 12.38 & 7.61 \\
\hline
\end{tabular}

*: Üst simge olan harfler $\% 5$ düzeyinde farklı grupları göstermektedir

Çeşitlerin tane verimleri ortalamaları 2015-16 üretim sezonunda $304.4 \mathrm{~kg} \mathrm{da}^{-1}$, 2016-17 üretim sezonunda ise $364.7 \mathrm{~kg} \mathrm{da}^{-1}$ olarak belirlenmiştir. 2015-16 üretim sezonunda en yüksek tane verimi $424 \mathrm{~kg} \mathrm{da}^{-1}$ ile Tarm92 çeşidinde, en düşük ise $211 \mathrm{~kg} \mathrm{da}^{-1}$ ile Novosadski565 çeşidinde belirlenmiştir. 2016-17 üretim sezonunda en yüksek tane verimi ise $527 \mathrm{~kg} \mathrm{da}^{-1}$ ile Scarpia çeşidinde, en düşük tane verimi ise $185 \mathrm{~kg} \mathrm{da}^{-1}$ ile Kral-97 çeşidinde belirlenmiştir.

Kuru tarım koşullarında sıcaklık, yağış miktarı $[9,10]$ ve yağışın dağılımı [11] verimi etkileyen önemli iklim faktörleridir. Özellikle serin iklim tahıllarının hızlı gelişim dönemi olan Mart-Haziran ayları arası iklim değerleri, diğer dönemlere göre daha belirleyici olmaktadır $[12,13,14,15]$. Denemenin ilk yılında sıcaklık verileri ikinci yıla ve uzun yıl ortalamalarına göre belirgin şekilde yüksek gerçekleșmiştir. Toplam yağış miktarları her iki yılda da uzun yıl ortalamalarına göre yaklaşık \%13 daha düşük kalmıştır. Ancak denemenin ikinci yılı Nisan ayı yağışı bir önceki yıla ve uzun y1l ortalamalarına göre yaklaşık 3 kat fazla olmuştur. Bu durum, başakta tane sayısı hariç, incelenen tüm özellik değerlerinin ikinci yıl yüksek çıkmasına neden olmuştur. 
Bitki boyu [16, 17], başak uzunluğu [18], başakta tane sayısı [19], bin tane ağırlığ1 $[19,20]$ ve hektolitre ağırlıkları [21] gibi verim özellikleri çeşitlerin genetik yapılarına bağlı olmakla birlikte genetik özelliklerinin çevreyle interaksiyonları $[15,22,23,24,25]$ verimi belirlemektedir. Bu çalışma sonucuna paralel olarak bazı çalışmalarda da hektolitre ağırlığının çevresel faktörlerden etkilenmediği [15] belirtilmiştir. Bitki boyu verimi etkileyen unsurlardan biri [26] olmakla birlikte, başaklanmadan sonra görülen yüksek yağış ve sulamalar saplar yeteri kadar güçlü değilse yatmalara neden olmaktadır [27]. Bu durum verimi ve hasadı olumsuz yönde etkilemektedir.

\section{SONUÇ}

Her iki yıl birlikte değerlendirildiğinde 2 siralı arpa çeşitlerinin verim ortalamaları $\left(350 \mathrm{~kg} \mathrm{da}^{-1}\right), 6$ sıralı çeşitlere $\left(323 \mathrm{~kg} \mathrm{da}^{-1}\right)$ göre daha yüksek bulunmuştur. Çeşitler bazında ise 6 sıralı Scarpia çeşidi $\left(422 \mathrm{~kg} \mathrm{da}^{-1}\right)$ ile 2 sıralı Tarm-92 çeşidi (406 kg da ${ }^{-1}$ ) öne çıkmıştır. Arpada önemli 1slah kriterlerinden biri bitki boyudur. Son yıllarda hayvancılıkta kaba yem açığı büyük bir sorundur. Kısa boylu çeşitler yerine bitki boyu 70-100 $\mathrm{cm}$ olan çeşitler 1slahta tercih edilmektedir. Bu bakımdan değerlendirildiğinde; verim yönünden de üçüncü sırada yer alan Aydanhanım çeşidi (355 $\mathrm{kg} \mathrm{da}^{-1}$ ) güçlü bir rakip olarak görülmektedir. Her iki yılda da en yüksek başakta tane sayısına sahip Kıral-97 çeşidi iklim yönünden daha uygun ve zengin besin içerikli topraklarda rekabette öne çıkması beklenmektedir.

\section{KAYNAKLAR}

[1] Zohary D, Hopf M. Domestication of plants inthe Old World, The origin and spread of cultivated plantsin West Asia, Europe and the Nile Valley, Clarendon Press,Oxford, England; 1993.

[2] Badr A, Rabey HE, Effgen S, Ibrahim HH, Pozzi C, Rohde W, Salamini F. On the origin and domestication history of barley (Hordeum vulgare), Molecular biology and evolution. 2000;17(4):499510.

[3] Food and Agriculture Organization. http://www.fao.org/faostat/en/\#data/QC/visualize Erișim tarihi: 23.04.2020.

[4] Yüksel S, İkincikarakaya SÜ, Sönmez AC, Belen S, Yıldırım Y. Eskişehir Ekolojik Koşullarında Bazı Arpa Hat ve Ceşitlerinin Verim ve Verim Öğeleri Üzerine Bir Araştırma. KSÜ Doğa Bilimleri Dergisi. 2017;20:252-257.

[5] Sirat A, Sezer İ. Bafra Ovası Koşullarına Uygu Arpa (Hordeum Vulgare L,) Ceşitleri. Anadolu Tarım Bilimleri Dergisi. 2009; 24(3):167-173.

[6] Ganusheva N, Dimova D, Lozanov I. Correlation and path analysis correlation quantitative characters in barley. Scientific works of Jubilee Scientific Session. 1990;65:58-63.

[7] Bilgin O, Korkut KZ. Bazı ekmeklik buğday (Triticum aestivum L,) çeşit ve hatlarının tane verimi ve bazı fenolojik özelliklerinin belirlenmesi. Tekirdağ Ziraat Fakültesi Dergisi. 2005;2(1):58-65.
[8] Sarı N, İmamoğlu A. Menemen Ekolojik Koşullarına Uygun İleri Arpa Hat ve Çeşitlerinin Belirlenmesi. Anadolu Ege Tarımsal Araştırma Enstitüsü Dergisi. 2009;19 (1):22-31.

[9] Tiryakioğlu M, Demirtaş B, Tutar H. Türkiye'deki buğday veriminin karşılaştırılması: Hatay ve Şanlıurfa illeri örneği. Süleyman Demirel Üniversitesi, Ziraat Fakültesi Dergisi. 2017;12(1): 56-67.

[10] Hay R, Porter J. The physiology of crop yield. 2nd ed, Blackwell Publishing, Oxford, UK, ISBN: 9781-405-10859-1.2006.

[11] Nielsen DC, Halvorson AD. Nitrogen fertility influence on water stress and yield of winter wheat. Agronomy Journal. 1991;83(6):1065-1070.

[12] Zhang H, Oweis T. Water-yield relations and optimal irrigation scheduling of wheat in the Mediterranean region. Agricultural Water Management. 1999;38(3):195-211.

[13] French RJ, Schultz JE. Water use efficiency of wheat in a Mediterranean-type environment, I, The relation between yield, water use and climate. Australian Journal of Agricultural Research. 1984;35(6):743-764.

[14] Soylu S, Sade B. İklim Değişikliğinin Tarımsal Ürünlere Etkisi Üzerine Bir Araştırma Projesi, Mevka TR51-12-TD-01 nolu Proje Sonuç Raporu, Konya, 2012. Available from: http://www.konyadayatirim.gov.tr [Erişim tarihi: 08.06.2017].

[15] Karahan T, Sabancı C. Güneydoğu Anadolu ekolojik koşullarında bazı arpa (Hordeum vulgare L,) çeşitlerinin verim ve verim öğelerinin belirlenmesi. Derim. 2010;27(1):1-11.

[16] Geçit HH, Adak MS. Osman Tosun Gen Bankasındaki 1-96 sira numaralı arpa materyalinde bazı morfolojik ve fizyolojik özelliklerin belirlenmesi. Ank. Üniv. Ziraat Fak. 1988;39:1-2.

[17] Çölkesen M, Öktem A, Engin A, Öktem AG, Demirağ V, Yürürdurmaz C, Çokkızgın A. Bazı arpa çeşitlerinin (Hordeum vulgare L, Kahramanmaraş ve Şanlıurfa koşullarında tarımsal ve kalite özelliklerinin belirlenmesi. 19 Mayıs Üniv. Ziraat Fak, Tarla Bitkileri Bilim Derneği, Türkiye II. Tarla Bitkileri Kongresi, 22-25 Eylül 1997, Samsun,

[18] Turgut İ, Konak C, Yılmaz R, Arabacı O. Büyük Menderes koşullarına uyumlu ve yüksek verimli arpa çeşitlerinin belirlenmesi üzerine araştırmalar. Türkiye II, Tarla Bitkileri Kongresi, 22-25 Eylül 1997 Samsun, 1997. P.80-83.

[19] Kaydan D, Yağmur M. Van ekolojik koşullarında bazı iki sıralı arpa çeşitlerinin (Hordeum vulgare L, conv, distichon) verim ve verim öğeleri üzerine bir araştırma. Ankara Üniversitesi Tarım Bilimleri Dergisi. 2007;13(3):269-278.

[20] Kandemir N. Tokat-Kazova şartlarına uygun maltlık arpa çeşitlerinin belirlenmesi. Gaziosmanpaşa Üniversitesi Ziraat Fakültesi Dergisi 2004;21(2):94-100.

[21] Akman Z, Kara B. Isparta yöresinde yetiştirilen Arpa köy çeşitlerinin verim ve verim öğelerinin 
belirlenmesi. Akdeniz Üni. Ziraat Fakültesi Dergisi. 2007;20(2):163-169.

[22] Whitman CE, Hatfield JL, Reginato RJ. Effect of slope position on the microclimate, growth, and yield of barley 1. Agronomy Journal. 1985;77(5):663-669.

[23] Akkaya A, Akten Ş. Erzurum yöresinde yetiştirilebilecek yazlık arpa çeşitlerinin belirlenmesi üzerine bir araştırma. Atatürk Üni. Zir. Fak. Der. 1990;17:1-4.

[24] Sirat A, Sezer İ. Determination of genotype by environment interactions and stabilities of some barley cultivars (Hordeum vulgare L.). Anadolu Tarım Bilimleri Dergisi. 2011;26(3):221-230.

[25] İmamoğlu A, Yılmaz N. Bursa ekolojik koşullarında bazı arpa (Hordeum vulgare L,) genotiplerinin verim ve bazı kalite özelliklerinin belirlenmesi. Anadolu Ege Tarımsal Araştırma Enstitüsü Dergisi. 2012;22(2):13-36.

[26] Kılınç M, Kırtok Y, Yağbasanlar T. Çukurova koşullarına uygun arpa çeşitlerinin geliştirilmesi üzerinde araştırmalar. 2. Arpa-Malt Semineri, 2527 Mayis 1992, Konya, 1992. p. 205-218.

[27] Nasr HG, Shands HL, Forsberg RA. Variation in kernel plumpness, lodging and other characteristics in sixrowed barley crosses. Crop Sci. 1972;12:159162. 